\title{
Biological evaluation of 5-fluorouracil nanoparticles for cancer chemotherapy and its dependence on the carrier, PLGA
}

This article was published in the following Dove Press journal:

International Journal of Nanomedicine

30 August 201I

Number of times this article has been viewed

\section{Lekha Nair K' \\ Sankar Jagadeeshan ${ }^{2}$ \\ S Asha Nair ${ }^{2}$ \\ GS Vinod Kumar'}

'Chemical Biology, Molecular Medicine Division, ${ }^{2}$ Cancer Research, Rajiv Gandhi Centre for Biotechnology, Poojappura, Thiruvananthapuram, Kerala, India
Correspondence: GSVinod Kumar Chemical Biology, Molecular Medicine Division, Rajiv Gandhi Centre for Biotechnology, Poojappura, Thiruvananthapuram 695 0I4, Kerala, India

Tel $+9 \mid$ 47| 2529526

Fax $+9|47| 2348096$

Email gsvinod@rgcb.res.in
Abstract: Nanoscaled devices have great potential for drug delivery applications due to their small size. In the present study, we report for the first time the preparation and evaluation of antitumor efficacy of 5-fluorouracil (5-FU)-entrapped poly (D, L-lactic-co-glycolic acid) (PLGA) nanoparticles with dependence on the lactide/glycolide combination of PLGA. 5-FU-loaded PLGA nanoparticles with two different monomer combinations, 50-50 and 90-10 were synthesized using a modified double emulsion method, and their biological evaluation was done in glioma (U87MG) and breast adenocarcinoma (MCF7) cell lines. 5-FU-entrapped PLGA 50-50 nanoparticles showed smaller size with a high encapsulation efficiency of $66 \%$, which was equivalent to that of PLGA 90-10 nanoparticles. Physicochemical characterization of nanoparticles using differential scanning calorimetry and X-ray diffraction suggested the presence of 5-FU in molecular dispersion form. In vitro release studies showed the prolonged and sustained release of 5-FU from nanoparticles with both the PLGA combinations, where PLGA 50-50 nanoparticles showed faster release. Nanoparticles with PLGA 50-50 combination exhibited better cytotoxicity than free drug in a dose- and time-dependent manner against both the tumor cell lines. The enhanced efficiency of PLGA 50-50 nanoparticles to induce apoptosis was indicated by acridine orange/ethidium bromide staining. Cell cycle perturbations studied using flow cytometer showed better S-phase arrest by nanoparticles in comparison with free 5-FU. All the results indicate that PLGA 50-50 nanoparticles possess better antitumor efficacy than PLGA 90-10 nanoparticles and free 5-FU. Since, studies have shown that long-term exposure of ailing tissues to moderate drug concentrations is more favorable than regular administration of higher concentration of the drug; our results clearly indicate the potential of 5-FU-loaded PLGA nanoparticles with dependence on carrier combination as controlled release formulation to multiplex the therapeutic effect of cancer chemotherapy.

Keywords: 5-FU, poly (D, L-lactic-co-glycolic acid), controlled release

\section{Introduction}

Cancer is one of the most challenging diseases to cure and the second leading cause of death in developed countries. Over the past few decades, it continues to be a worldwide health problem in spite of the rising number of nanoscaled technologies. ${ }^{1}$ Chemotherapy is the major therapeutic approach for the treatment of localized and metastasized cancers. Even though the development of both diagnostic and therapeutic tools is on the rise, nonselective distribution of drugs, enhanced drug toxicity, and undesirable side effects to normal tissues aggravate the challenges for chemotherapy. To prevail over this, carrier-mediated drug delivery offers a number of design opportunities for engineering the delivery of a particular drug, with enhanced therapeutic effect. ${ }^{2}$ It is proven that the entrapment of these anticancer agents in particles of nanometer and 
micrometer range can control their release. Hence, in the area of chemotherapy, nanotechnology could be an alternative to improve the life expectancy of the cancer patients.

5-Fluorouracil (5-FU) a pyrimidine analog, is one of the broad spectrum anticancer drugs ${ }^{3-5}$ used in the treatment of malignancies like glioblastoma ${ }^{6}$ and breast cancer. ${ }^{7}$ Since 5-FU interferes with DNA synthesis, it principally acts as a thymidylate synthase inhibitor. ${ }^{8,9}$ However, short half-life, wide distribution, and various side effects ${ }^{10-12}$ limit its medical applicability. To overcome the above mentioned limitations, an ample number of studies has been carried out on sustained drug delivery systems for $5-\mathrm{FU}^{13-15}$ using polymers like poly (D, L-lactic-co-glycolic acid) (PLGA). PLGA, which is a US Food and Drug Administration-approved polymer, has successfully been used as a carrier for drug delivery applications for a wide range of drugs, including 5-FU, for more than a decade now. ${ }^{16}$ One of the advantages of this polymer is that by regulating the lactide to glycolide ratio the degradation rate can be regulated. ${ }^{17,18}$ 5-FU-loaded PLGA microspheres have been developed and studied for stereotactic intracerebral implantation in C6 glioma bearing rats with very promising results as far as survival, welfare, and future applications were forecast. ${ }^{19-21}$ Although 5-FU-loaded microparticles are envisaged as having great potential for drug delivery, their suitability for directing the drug to the tissues or cells via systemic circulation or mucous membrane remain hindered due to their large size. On the contrary, nanoscaled particles are capable of cellular internalization along with permeation of connective tissues without blocking the capillaries. Furthermore, due to leaky endothelial tissues that surround the tumor, these nanoparticles can pass through the vasculature and accumulate in the solid tumors. Studies have shown that nanoparticles carrying anticancer agents show prolonged drug retention in the tumors, which diminishes tumor growth and thereby increases the life-span of tumor-bearing animals. ${ }^{22-24}$ Although studies are in progress to increase the bioavailability of 5-FU with nanoparticle carrier systems, ${ }^{25,26}$ data showing biological efficacy of PLGA nanoparticles as a carrier for 5-FU have hardly been reported. Moreover, dependence of these nanoparticles on the combination of PLGA used has not been investigated so far.

The main aim of this work was to develop a PLGAbased nanoparticle delivery system for 5-FU with two different monomeric combinations and to examine the effect of lactide to glycolide ratio on their drug release and cytotoxicity. 5-FU-entrapped PLGA nanoparticles, using PLGA 50-50 and 90-10, were prepared using the double emulsion method. These nanoparticles were further characterized for their size, morphology, and charge using a particle size analyzer and transmission electron microscope (TEM). The thermal behavior was studied using differential scanning calorimetry (DSC) and X-ray diffraction (XRD). In vitro drug release studies were performed to compare the release rate of 5-FU from the two polymeric combinations. For biological evaluation, glioblastoma (U87MG) and breast cancer (MCF7) cell lines were selected. The cellular uptake of these nanoparticles was done with a fluorescent dye using confocal microscopy. Controlled release of the drug from the nanoparticles and its antitumoral efficacy when compared with free 5-FU was analyzed using MTT (3-[4, 5-dimethylthiazol-2-yl]-2, 5-diphenyltetrazolium bromide) assay followed by acridine orange/ethidium bromide $(\mathrm{AO} / \mathrm{EB})$ staining in both the cell lines. The perturbations in cell cycle on treatment with 5-FU nanoformulations were analyzed by flow cytometer.

\section{Materials and methods Materials}

PLGA polymer with co-polymerization ratios 50-50 and 90-10 (lactic/glycolic) $\mathrm{M}_{\mathrm{w}}$ 10-75 kDa, Pluronic ${ }^{\circledR}$ F-68, rhodamine, 5-FU, MTT, Dulbecco's modified Eagle's medium (DMEM), trypsin-ethylenediaminetetraacetic acid (EDTA) and 4',6-diamidino-2-phenylindole (DAPI) were purchased from Sigma-Aldrich (Steinheim, Germany), and fetal bovine serum (FBS) from Gibco (Life Technologies AG, Basel, Switzerland). All organic solvents were of high performance liquid chromatography grade.

\section{Preparation of 5-FU-loaded PLGA polymer nanoparticles}

5-FU-loaded PLGA nanoparticles with both the copolymeric ratios were prepared by the double emulsion (w/o/w) method. Briefly, 5-FU dissolved in water $(1 \% \mathrm{w} / \mathrm{v})$ was added to PLGA dissolved in dichloromethane $(2 \% \mathrm{w} / \mathrm{v})$ by vortexing to form the primary emulsion (w/o). This emulsion was then mixed with the aqueous phase $(30 \mathrm{~mL})$ containing Pluronic F-68 $(1 \% \mathrm{v} / \mathrm{v})$ as the surfactant to form the secondary emulsion $(\mathrm{w} / \mathrm{o} / \mathrm{w})$. This emulsion was further disrupted into fine droplets by sonication at $130 \mathrm{~W}$ and $20 \mathrm{kHz}$ power supply for 2 minutes, and the organic solvent was evaporated completely by stirring the emulsion overnight. The nanoparticles were washed three times in distilled water by ultracentrifugation at 40,000 rpm (Optima ${ }^{\mathrm{TM}}-100 \mathrm{~K}$ Ultracentrifuge, Beckman Coulter Inc, Brea, CA) at $4^{\circ} \mathrm{C}$ for 1 hour. The nanoparticle suspension was lyophilized (VirTis ${ }^{\circledR}$, AdVantage, Warminster, PA) at a condenser temperature of $-55^{\circ} \mathrm{C}$ and 
pressure of 720 mTorr with 5\% (w/v) sucrose as a cryoprotectant to obtain the dry powder.

\section{Characterization of nanoparticles}

\section{Particle size and size distribution}

The images of 5-FU-entrapped PLGA nanoparticles were taken using a JEM-1011 TEM (JEOL, Tokyo, Japan). For $\mathrm{TEM}$, the samples of the nanoparticle suspension in Milli- $\mathrm{Q}^{\circledR}$ (Millipore Corporation, Billerica, MA) water at $25^{\circ} \mathrm{C}$ were dropped onto formvar-coated grids, and measurements were taken only after the samples were completely dried. The size distribution and zeta potential of these nanoparticles were analyzed using a Delsa ${ }^{\mathrm{TM}}$ Nano particle size analyzer (Beckman Coulter, Inc).

\section{Determination of drug encapsulation efficiency}

The amount of 5-FU entrapped in the nanoparticles was determined by the separation of 5-FU-loaded nanoparticles from the suspension containing free 5-FU by centrifugation. The suspension obtained after solvent evaporation was centrifuged, and the amount of free 5-FU in the supernatant was determined using an ultraviolet (UV) spectrophotometer (Perkin Elmer, Waltham, MA) at a wavelength of $267 \mathrm{~nm}$. The concentration of free drug in the supernatant was obtained by comparing the absorption of the supernatant to the standard curve relating absorption and 5-FU concentration. The amount of drug entrapped into nanoparticles was calculated as the difference between the drug used for formulation and the amount of drug in the supernatant and was expressed as encapsulation efficiency. The yield of nanoparticles was calculated as the ratio of the amount of nanoparticles recovered to the total amount of polymer and 5-FU used in formulation.

\section{DSC analysis}

DSC thermograms of free 5-FU, empty nanoparticles, and 5-FU-loaded PLGA nanoparticles were compared to analyze the physicochemical behavior of nanoparticles. DSC thermograms were obtained using an automatic thermal analyzer system (Pyres 6 DSC, Perkin-Elmer). Samples were crimped in standard aluminum pans and heated from $20^{\circ} \mathrm{C}$ to $300^{\circ} \mathrm{C}$ at a heating rate of $15^{\circ} \mathrm{C} /$ minute under constant purging of $\mathrm{N}_{2}$ at $20 \mathrm{~mL} /$ minute. An empty pan, sealed in the same way as the sample, was used as a reference.

\section{XRD}

The crystalline nature of free 5-FU and 5-FU nanoparticle formulations was compared by powder XRD patterns acquired at room temperature on an X-ray diffractometer
(X'pert PRO, PANalytical, Lelyweg, the Netherlands) using $\mathrm{Cu} \mathrm{K} \alpha$ radiation $5^{\circ} \mathrm{C}-60^{\circ} \mathrm{C}$ in continuous mode with a step size of $0.02^{\circ} 2 \theta$ and step time of 5 seconds.

\section{In vitro drug-release studies}

To analyze the dependence of 5-FU release from PLGA combination, in vitro release studies were conducted. 5-FU-loaded PLGA nanoparticles (50 mg) were dispersed in $50 \mathrm{~mL}$ of phosphate buffered saline (PBS) (pH 7.4) and incubated at $37^{\circ} \mathrm{C}$ under continuous shaking of $60 \mathrm{rpm}$. At predetermined intervals, $1 \mathrm{~mL}$ of release medium was collected and replaced with fresh PBS to maintain sink conditions. The newly collected release media was centrifuged, and the amount of 5-FU released was determined by UV spectrophotometer at $267 \mathrm{~nm}$. Using a standard curve for 5-FU, the cumulative amount of 5-FU released was evaluated.

\section{Cells and cell culture}

U87MG glioma cells and MCF7 breast adenocarcinoma cells were cultured in DMEM supplemented with $10 \% \mathrm{FBS}$ at $37^{\circ} \mathrm{C}$ under a humidified atmosphere containing 5\% carbon dioxide. Until reaching $70 \%$ confluence in tissue culture flasks, the cells were trypsinized with buffered saline solution containing $0.25 \%$ trypsin and $0.03 \%$ EDTA. After that, the cells were plated to culture plate as desired and allowed to attach for 24 hours. The dispersed nanoparticle suspensions in cell culture medium were then diluted to specific concentrations and immediately added into the cells. After incubation for predetermined durations, the cells were subsequently analyzed for the cellular uptake, viability, and morphological changes.

\section{Cellular uptake studies}

Since 5-FU is a nonfluorescent drug, rhodamine-entrapped PLGA nanoparticles using both the combinations were prepared in order to study the cellular uptake. U87MG glioma cells and MCF7 breast adenocarcinoma cells were grown at a density of $5 \times 10^{3}$ cells/well in the same way as described above into 12 -well plates containing sterile glass coverslips. The cells were incubated with $10 \mu \mathrm{mol} / \mathrm{L}$ of rhodamine-entrapped nanoparticles at $37^{\circ} \mathrm{C}$ for 2 hours and counterstained with DAPI. The cells were then washed twice with PBS to remove nanoparticles not taken up by the cells, fixed with 4\% paraformaldehyde for 8 minutes, and again washed twice with PBS. Cells were mounted using glycerol, and the intracellular rhodamine fluorescence in the cells was examined under a confocal laser scanning microscope (TCS SP2; Leica Microsystems, Wetzlar, Germany) at a magnification of $60 \times$ and scan speed of $400 \mathrm{~Hz}$. 


\section{Cytotoxicity assay}

MTT reduction assay was performed to assess cell viability. Briefly, cells were seeded $\left(5 \times 10^{3}\right.$ cells/well $)$ in a 96 -well culture plate and incubated for 24 hours. Cells were given treatment with formulations of 5-FU $(10-150 \mu \mathrm{M})$ for 24,48 , and 72 hours. Thereafter, MTT at a concentration of $5 \mathrm{mg} / \mathrm{mL}$ in PBS (pH 7.4) was added to each well $(10 \% \mathrm{v} / \mathrm{v})$, and the cells were further incubated for 4 hours at $37^{\circ} \mathrm{C}$. After removing the unreacted medium, the blue crystals were dissolved in $100 \mu \mathrm{L}$ isopropyl alcohol, and optical density was measured at $570 \mathrm{~nm}$. Cell viability (\%) related to control wells containing cell culture medium without treatment was calculated by $[A]_{\text {test }} /[A]_{\text {control }} \times 100$, where $[A]_{\text {test }}$ is the absorbance of the test sample and $[A]_{\text {control }}$ is the absorbance of the control sample. Six replicates were prepared for each sample.

\section{$\mathrm{AO} / \mathrm{EB}$ assay}

$\mathrm{AO} / \mathrm{EB}$ assay is reported to be a reliable method for the quantification of apoptosis. ${ }^{27,28}$ Thus, for fluorescence cytochemical study, cells were seeded in a $35 \mathrm{~mm}$ culture dish and 5-FU treatment $(100 \mu \mathrm{M})$ was given for 24 hours. Medium was removed, and the cells were washed with PBS. The cells were then given a combined staining of $\mathrm{AO}(50 \mathrm{mg} / \mathrm{mL})$ and $\mathrm{EB}(5 \mathrm{mg} / \mathrm{mL})$ for 5 minutes at room temperature and examined by an inverted fluorescence microscope (DMI 4000B; Leica Microsystems) at a magnification of 20x.

\section{Cell-cycle analysis}

For flow cytometric analysis, $10^{6}$ cells were seeded in $60-\mathrm{mm}$ culture dishes. 5-FU treatment $(50 \mu \mathrm{M})$ was given for 24 hours, and the cells were harvested and fixed with $70 \%$ ethanol for 1 hour. The fixed cells were then given RNase A $(100 \mathrm{mg} / \mathrm{mL})$ treatment for 1 hour followed by incubation with propidium iodide $(10 \mathrm{mg} / \mathrm{mL})$, in the dark, for 15 minutes. Finally, DNA content of the cells was analyzed using FACSAria ${ }^{\mathrm{TM}}$ I special order system (BD Biosciences, San Jose, CA).

\section{Statistical analysis}

All the measurements were done in triplicate, and the results were expressed as arithmetic mean \pm standard error of the mean.

\section{Results}

\section{Characteristic parameters of} nanoparticles are independent of lactide/ glycolide ratio of PLGA

5-FU nanoparticles having PLGA as a carrier were successfully prepared in the nanometer range using the double emulsion (w/o/w) method. 5-FU-entrapped PLGA nanoparticles showed an average size of $150 \mathrm{~nm}$ and $190 \mathrm{~nm}$ with 50-50 and 90-10 combination (Figure 1). Nanoparticles with both the combinations were spherical, with a narrow size distribution and low polydispersity index (Figure 2). A good yield of nanoparticles with similar encapsulation efficiency in the range of $66 \%$ was obtained for both the combinations. These results indicate the independence of size, polydispersity, and encapsulation of nanoparticles of the lactide to glycolide ratio of PLGA. Also, compared with blank PLGA nanoparticles, no significant change in size, polydispersity, and surface charge was seen on entrapping the nanoparticles with drug (Table 1).

To assess the thermal behavior of the nanoparticles, DSC was done on free 5-FU, blank PLGA nanoparticles, and 5-FUentrapped PLGA nanoparticles. As shown in Figure 3, pure 5-FU showed the presence of an endothermic peak at $280.1^{\circ} \mathrm{C}$, whereas both vacant and drug-entrapped nanoparticles showed a peak at $50^{\circ} \mathrm{C}$. The peak near $280^{\circ} \mathrm{C}$ represents the melting of 5-FU, whereas in the case of the empty and the 5-FU-loaded nanoparticles, the peak around $50^{\circ} \mathrm{C}$ (glass transition temperature $\left[\mathrm{T}_{\mathrm{g}}\right]$ of PLGA) are typical of the polymer. The DSC thermograms suggested the presence of 5-FU in molecular dispersion form inside the polymer matrix.

To study the effect of 5-FU entrapment on its crystalline behavior, XRD patterns of free 5-FU, blank PLGA 50-50, and 5-FU-loaded PLGA 50-50 nanoparticles were obtained and compared. For the free 5-FU, the diffractograms exhibited an intense peak at the $2 \theta$ values near 28 due to its crystalline nature, while vacant as well as drug-entrapped nanoparticle formulations showed no characteristic peak of 5-FU, supporting DSC results of the presence of drug in solid dispersion form (Figure 4).

\section{5-FU-entrapped PLGA 50-50 nanoparticles showed faster release}

One of the major aims of this study was to analyze the effect of change in the lactide/glycolide ratio on the release pattern

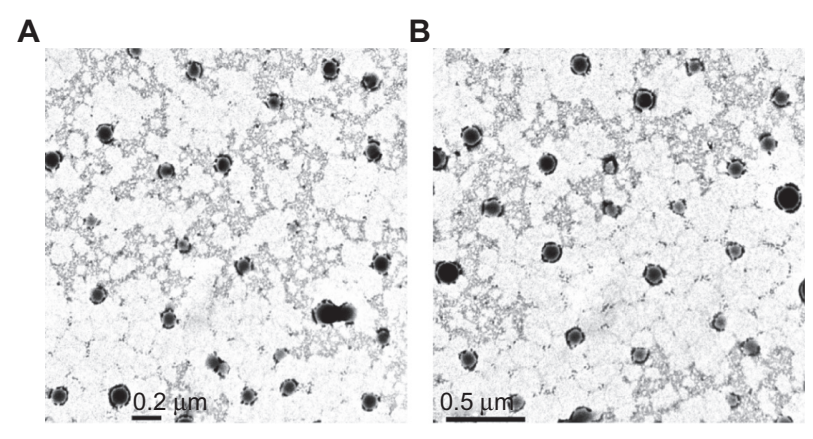

Figure I Transmission electron microscopy images of 5-FU-entrapped PLGA 50-50 (A) and PLGA 90-10 nanoparticles (B).

Abbreviations: FU, 5-fluorouracil; PLGA, poly (D, L-lactic-co-glycolic acid). 

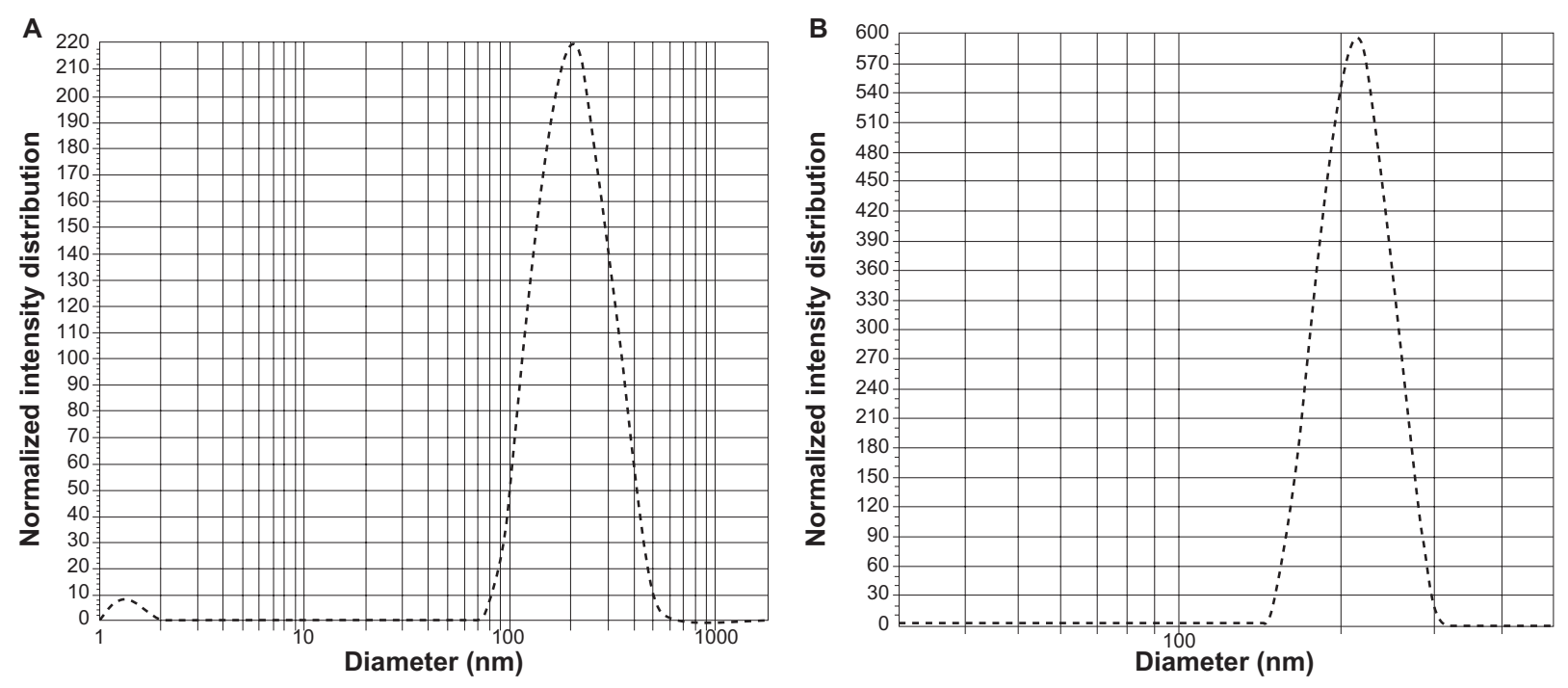

Figure 2 Polydispersity graphs of 5-FU-entrapped PLGA 50-50 (A) and PLGA 90-10 nanoparticles (B). Abbreviations: FU, 5-fluorouracil; PLGA, poly (D, L-lactic-co-glycolic acid).

of 5-FU from PLGA nanoparticles. It was seen that nanoparticles with both the combinations continued to release 5-FU for a period of 1 week (Figure 5). On comparing the release pattern of 5-FU from PLGA 50-50 and 90-10 nanoparticles, it was observed that within 48 hours $25 \% 5$-FU was released from PLGA 50-50 nanoparticles compared with 20\% of 5-FU from PLGA 90-10 nanoparticles. At the end of 1 week, only $65 \%$ of the drug was released in the case of 90:10 nanoparticles compared with the release of $85 \% 5-\mathrm{FU}$ from 50-50 nanoparticles. This variation in the release rate was because of the variation in the lactide/glycolide ratio, which alters the degradability of PLGA. Since the 50-50 combination contains a higher percentage of the hydrophilic block polyglycolide compared with 90-10, which contains a major percentage of hydrophobic polylactide, it shows faster degradability resulting in a faster release of 5-FU.

\section{Internalization of 5-FU nanoparticles is independent of the lactide/glycolide ratio of PLGA}

Since 5-FU is a nonfluorescent drug, cellular uptake of these nanoparticles in U87MG and MCF7 cell lines was studied using rhodamine dye. Nanoparticles were internalized as early as 2 hours after incubation, which was evident from the red fluorescence of rhodamine in the cell cytoplasm. The cellular uptake and subsequent localization of rhodamine-PLGA nanoparticles in U87MG and MCF7 cells are represented in Figures 6 and 7. It was observed that PLGA nanoparticles were efficiently taken up by both the cell lines, irrespective of the lactide/glycolide ratio of PLGA used as a carrier.

\section{Loss of viability by 5 -FU nanoparticles is monomeric concentration dependent}

We further analyzed the cytotoxic effect of 5-FU nanoparticles, and polymer nanoparticles with no drug showing more cell viability, proving biocompatibility of PLGA. On the contrary, 5-FU-entrapped nanoparticles exhibited higher cytotoxicity than that of free 5-FU over a range of experimental concentrations against two tumor cell lines. When U87MG cells were exposed to nanoparticles for 24 hours, viability of $72 \%$ for PLGA $50-50$ and $74.6 \%$ for $90-10$ nanoparticles at a concentration of $25 \mu \mathrm{mol} / \mathrm{L}$, compared with free 5 -FU (78.5\%), was observed. Further incubation for 48 hours showed a decrease in cell viability in a concentrationdependent manner, with nanoparticles maintaining higher cytotoxicity. At the end of 3 days, compared with $54.2 \%$ cell viability for free 5-FU, a cell viability of $48.3 \%$ and $50.9 \%$

Table I Characterization of nanoparticles

\begin{tabular}{llllll}
\hline Sample & $\begin{array}{l}\text { Encapsulation } \\
\text { Efficiency \% }\end{array}$ & Yield \% & $\begin{array}{l}\text { Mean Diameter } \\
(\mathbf{n m})\end{array}$ & $\begin{array}{l}\text { Polydispersity } \\
\text { Index }\end{array}$ & $\begin{array}{l}\text { Zeta } \\
\text { Potential }\end{array}$ \\
\hline Blank PLGA nanoparticles & - & $86.4 \pm 2.3$ & $135.4 \pm 5.6$ & $0.031 \pm 0.013$ & $-24.5 \pm 4.3$ \\
5-FU PLGA 50-50 nanoparticles & $66.65 \pm 0.90$ & $88.6 \pm 1.78$ & $150.55 \pm 6.01$ & $0.064 \pm 0.029$ & $-18.3 \pm 6.1$ \\
5-FU PLGA 90-10 nanoparticles & $65.53 \pm 0.73$ & $88.4 \pm 2.13$ & $190.30 \pm 7.35$ & $0.035 \pm 0.016$ & $-21.3 \pm 3.5$ \\
\hline
\end{tabular}

Abbreviations: FU, 5-fluorouracil; PLGA, poly (D, L-lactic-co-glycolic acid). 


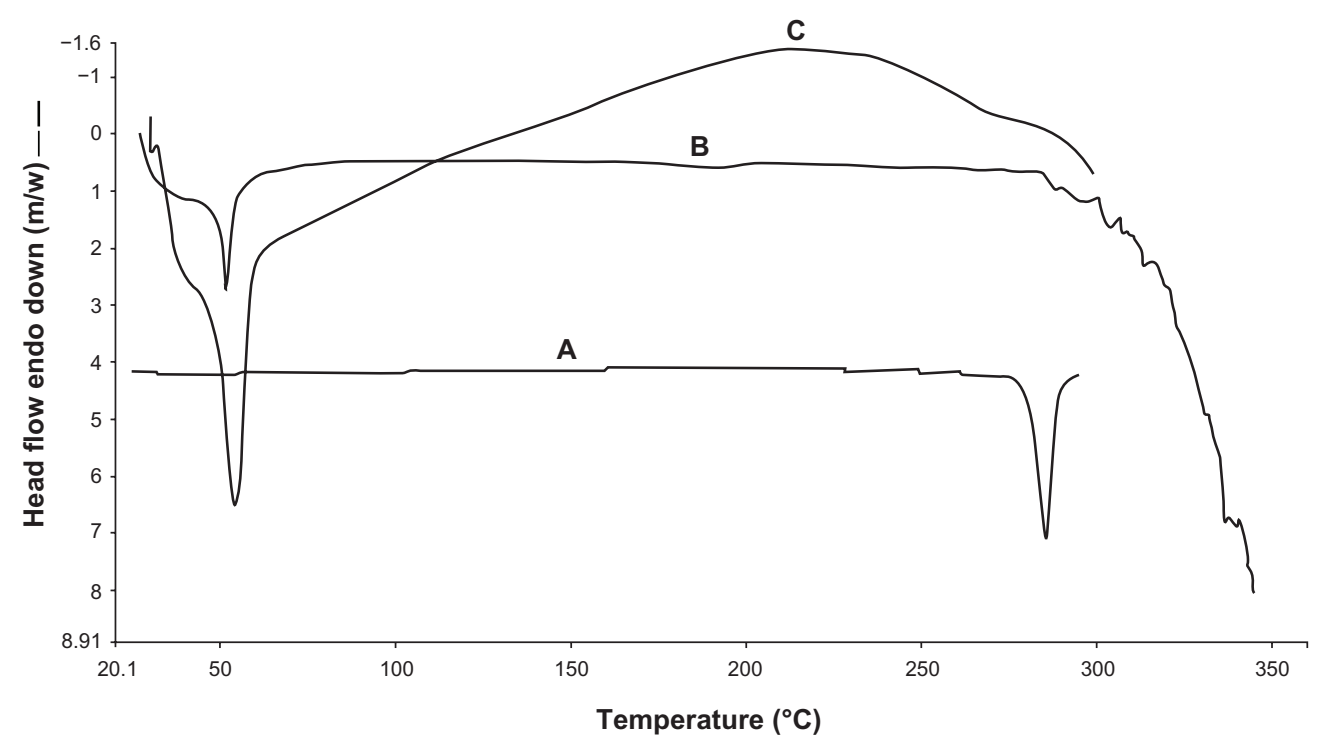

Figure 3 Differential scanning calorimetry thermograms of free 5-FU (A), vacant 5-FU PLGA nanoparticles (B), and 5-FU-entrapped PLGA nanoparticles (C). Abbreviations: FU, 5-fluorouracil; PLGA, poly (D, L-lactic-co-glycolic acid).

was seen for 5-FU PLGA 50-50 and 90-10 nanoparticles at $25 \mu \mathrm{mol} / \mathrm{L}$, respectively (Figure 8).

Similarly, our results with MCF7 breast cancer cells also showed that PLGA nanoparticles containing 5-FU exhibited better toxicity than that of free 5-FU. Incubation for 24 hours with 5-FU-entrapped nanoparticles showed higher cytotoxicity $(20 \%-21 \%)$ when compared with cell death caused by $10 \mu \mathrm{mol} / \mathrm{L}$ of free drug (10\%). However, 72 hours treatment for 50-50 nanoparticles showed highest cytotoxicity $(61.5 \%)$ compared with free 5-FU (48.8\%) and 90-10 nanoparticles $(50.3 \%)$ (Figure 9). Interestingly, our study using PLGA 90-10 nanoparticles showed higher cell viability than 50-50 nanoparticles; this may be due to its higher lactide

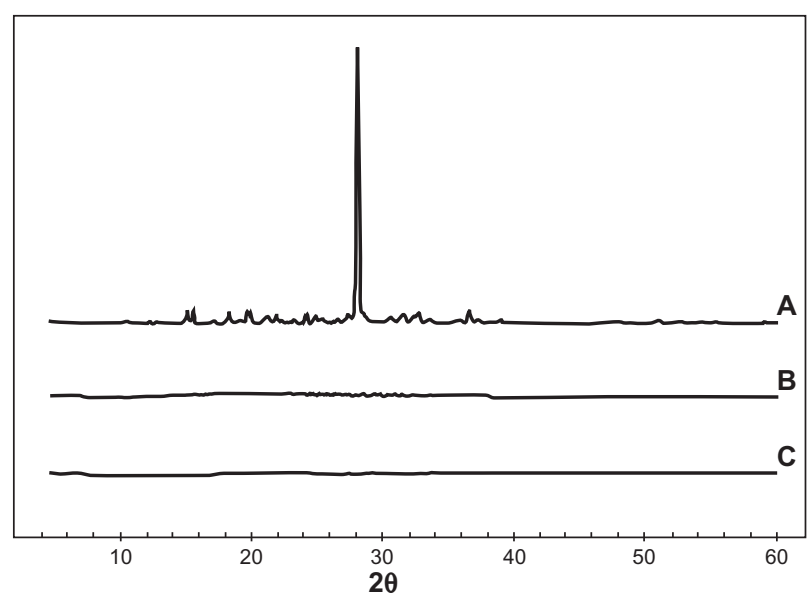

Figure 4 X-ray diffractograms of free 5-FU (A), vacant PLGA 50-50 nanoparticles (B), and 5-FU entrapped PLGA 50-50 nanoparticles (C).

Abbreviations: FU, 5-fluorouracil; PLGA, poly (D, L-lactic-co-glycolic acid). content, contributing to slower release as our results depict. Our results thereby justify that these nanoparticles may have an enhanced potential as a chemotherapeutic compared with free drug.

\section{5-FU nanoparticles induced apoptosis in tumor cell lines}

To further characterize the cytotoxic effect of 5-FU nanoparticles, cells were incubated with $100 \mu \mathrm{mol} / \mathrm{L}$ of 5-FU formulations for 24 hours, and a fluorescence cytochemical study was done. Cytochemical staining using $\mathrm{AO}$ and $\mathrm{EB}$ revealed characteristic chromatin condensation. EB was selectively taken up by apoptotic cells and stained the condensed nuclei, whereas the

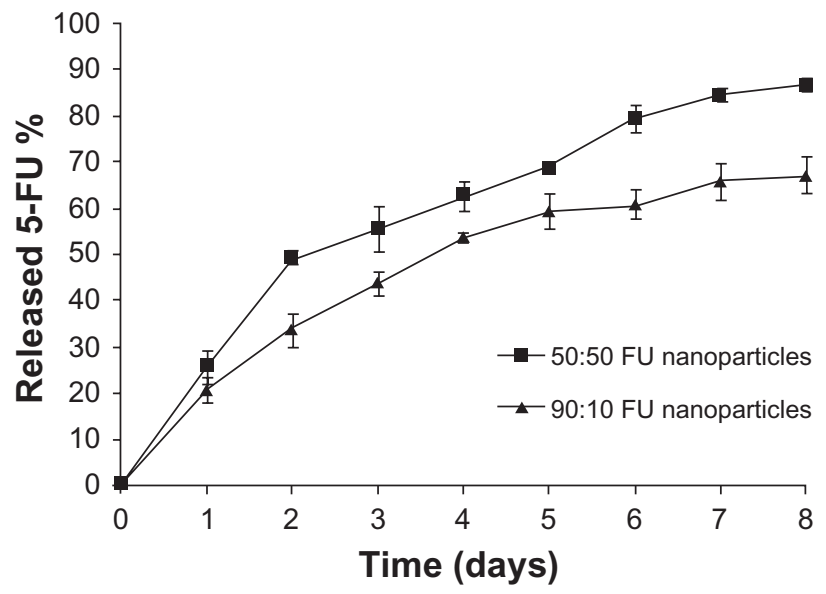

Figure 5 In-vitro drug-release pattern of 5-FU from 5-FU-entrapped PLGA nanoparticles.

Abbreviations: FU, 5-fluorouracil; PLGA, poly (D, L-lactic-co-glycolic acid). 

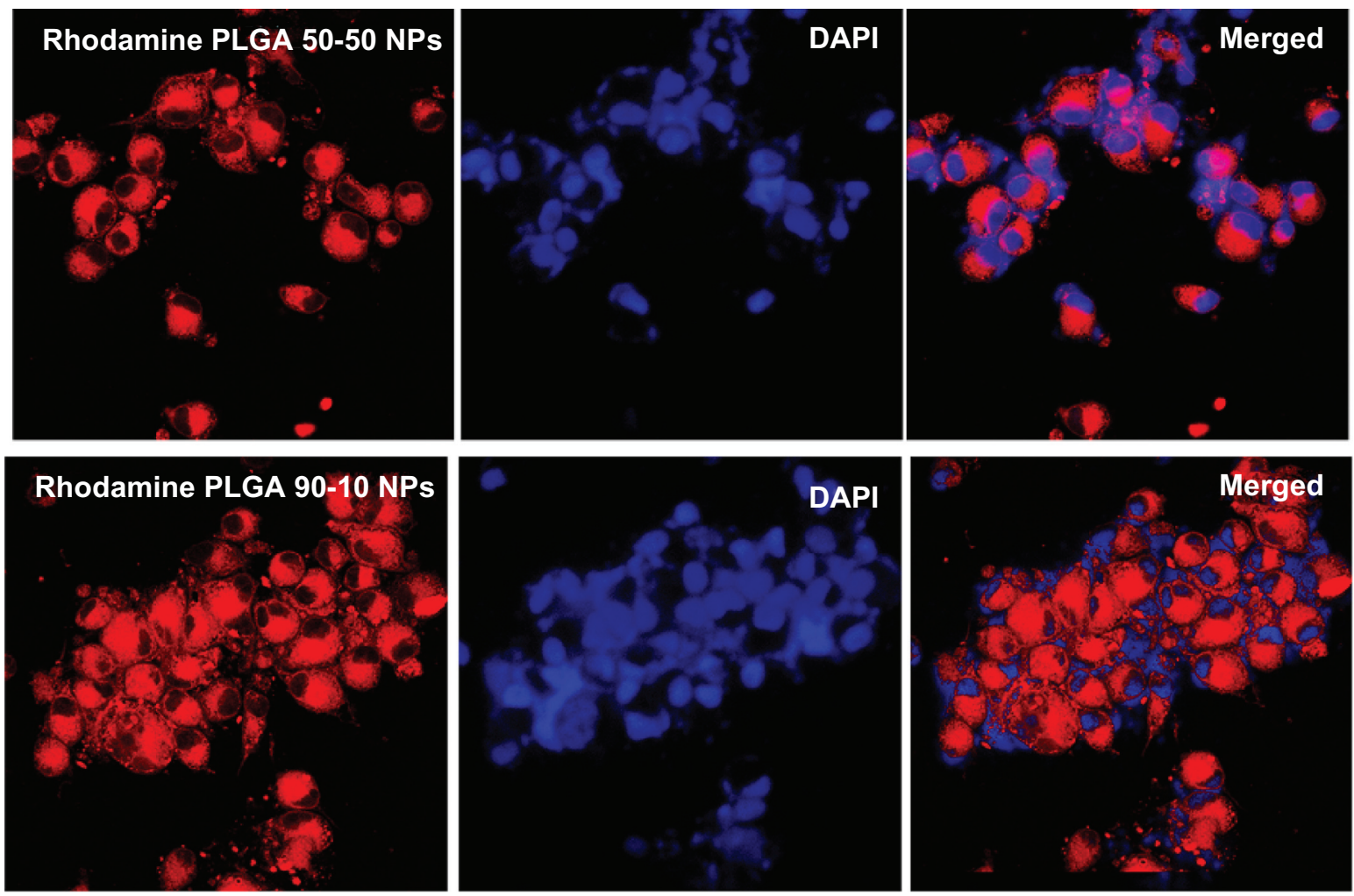

Figure 6 Confocal images of U87MG cells after 2 hours incubation with rhodamine-entrapped PLGA NPs. Abbreviations: DAPI, 4',6-diamidino-2-phenylindole; NP, nanoparticle; PLGA, poly (D, L-lactic-co-glycolic acid).
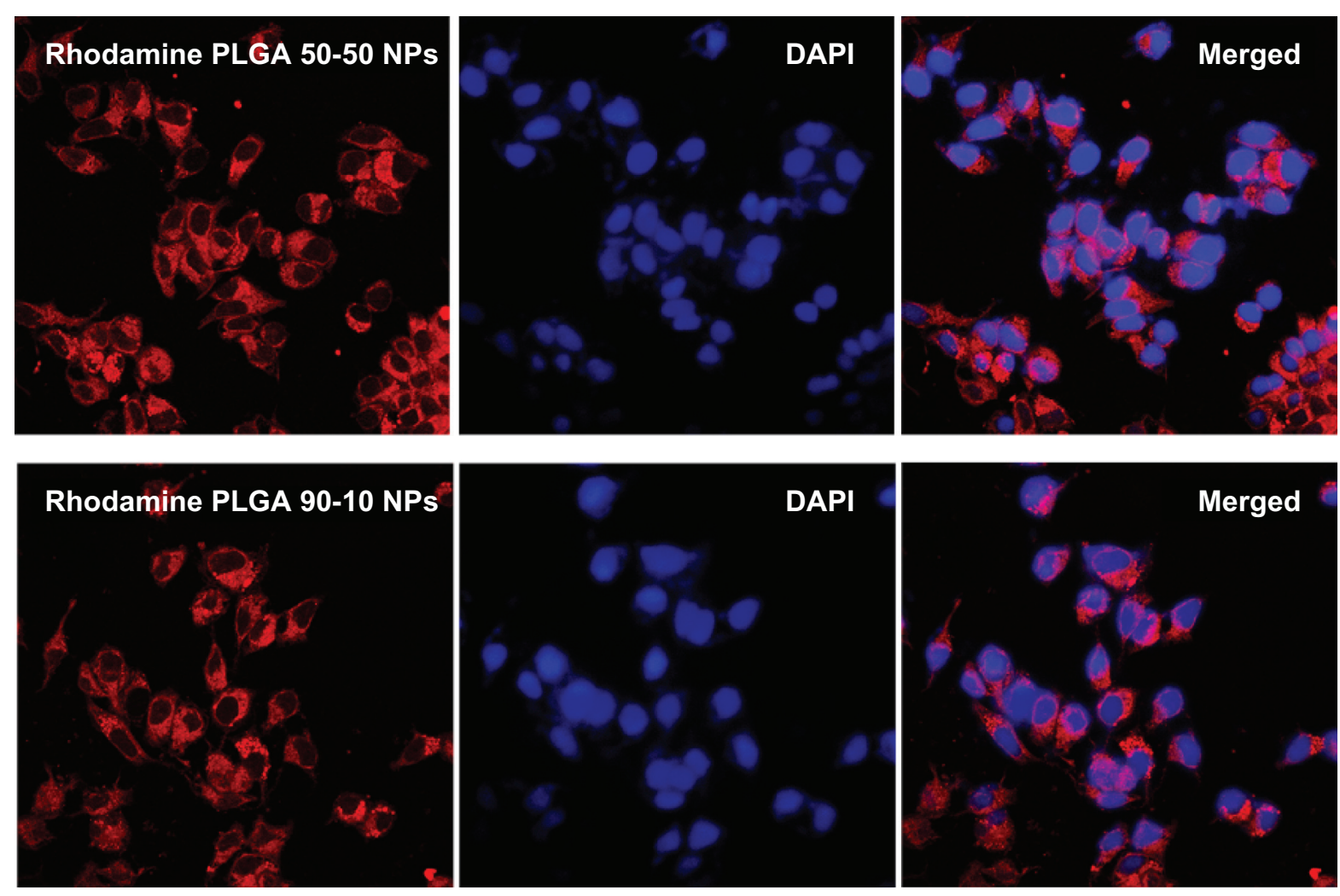

Figure 7 Confocal images of MCF7 cells after 2 hours incubation with rhodamine-entrapped PLGA NPs.

Abbreviations: DAPI, 4',6-diamidino-2-phenylindole; NP, nanoparticle; PLGA, poly (D, L-lactic-co-glycolic acid). 

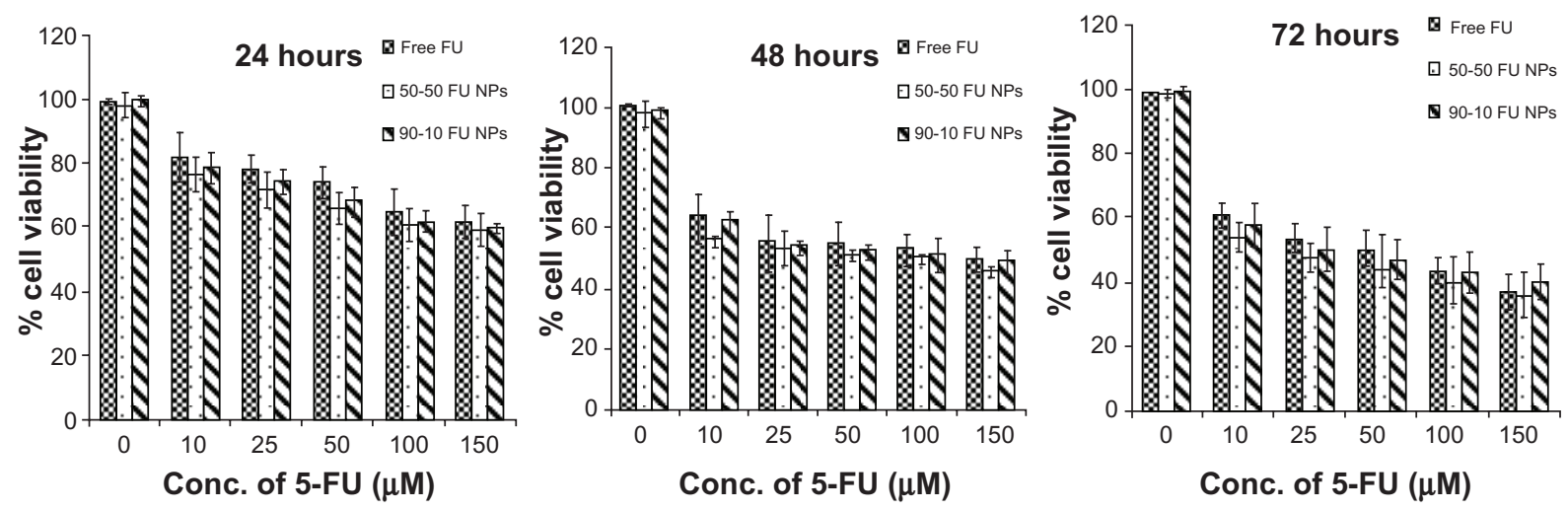

Figure 8 Cell viability of U87MG cells treated with 5-FU-entrapped PLGA 50-50 and 90-10 NPs compared with free 5-FU (mean \pm standard deviation; $n=6$ ). Abbreviations: Conc, concentration; FU, 5-fluorouracil; NP, nanoparticle; PLGA, poly (D, L-lactic-co-glycolic acid).

control cells had only taken up AO (97\%). 5-FU PLGA 50-50 nanoparticles showed less viability, with $50 \%$ and $23 \%$ death in U87MG and MCF7 cells, respectively. On the other hand, $45 \%$ and $7 \%$ of U87MG and MCF7 cells showed condensed chromatin on free 5-FU treatment (Figures 10 and 11).

\section{5 -FU in nanoform induced significant S-phase arrest in the cell division cycle}

Nuclear condensation results indicated that the cells may have undergone DNA damage. Therefore, we performed cellcycle analysis to identify whether treated cells underwent a synthetic phase arrest. We observed that cells passed through the mitotic division but were arrested at the S-phase, and therefore determined the drug was acting as a DNA synthase inhibitor. 5-FU PLGA nanoparticles caused higher S-phase arrest (27.2\% and 24.1\%) in U87MG cells. In MCF7 cells also, a significant increase in the $\mathrm{S}$ phase was seen. Here also, PLGA 50-50 nanoparticles induced considerably higher (42.0\%) arrest compared with 90-10 nanoparticles (30.5\%) and free drug $(20.6 \%)$, respectively (Figure 12 ).

\section{Discussion}

Chemotherapy is one of the treatment methods for cancer, which is one of the leading causes of death in the world. But side effects associated with overdosing and low therapeutic index restrict the use of chemotherapeutic agents. 5-FU, sold under the brand names Adrucil ${ }^{\circledR}$ and Efudex $^{\circledR}$, is an anticancer drug used in the treatment of a variety of cancers. But side effects such as dermatitis, cardiac toxicity, and damage of the central nervous system limit its applications. ${ }^{29}$ Existing reports have shown the potential of controlled release systems ${ }^{30,31}$ using polymers to avoid the side effects caused due to overdosing and repeated infusion of drug. Although PLGA-based 5-FU-loaded microspheres and implant systems ${ }^{31-33}$ have shown promising results compared with free drug, the literature still lacks studies evaluating the efficiency of 5-FU particles at the nano level. Nanoparticles possess the ability to permeabilize the cells more efficiently than microspheres due to their smaller size, which facilitates administration of large quantities of drug to give better efficacy.
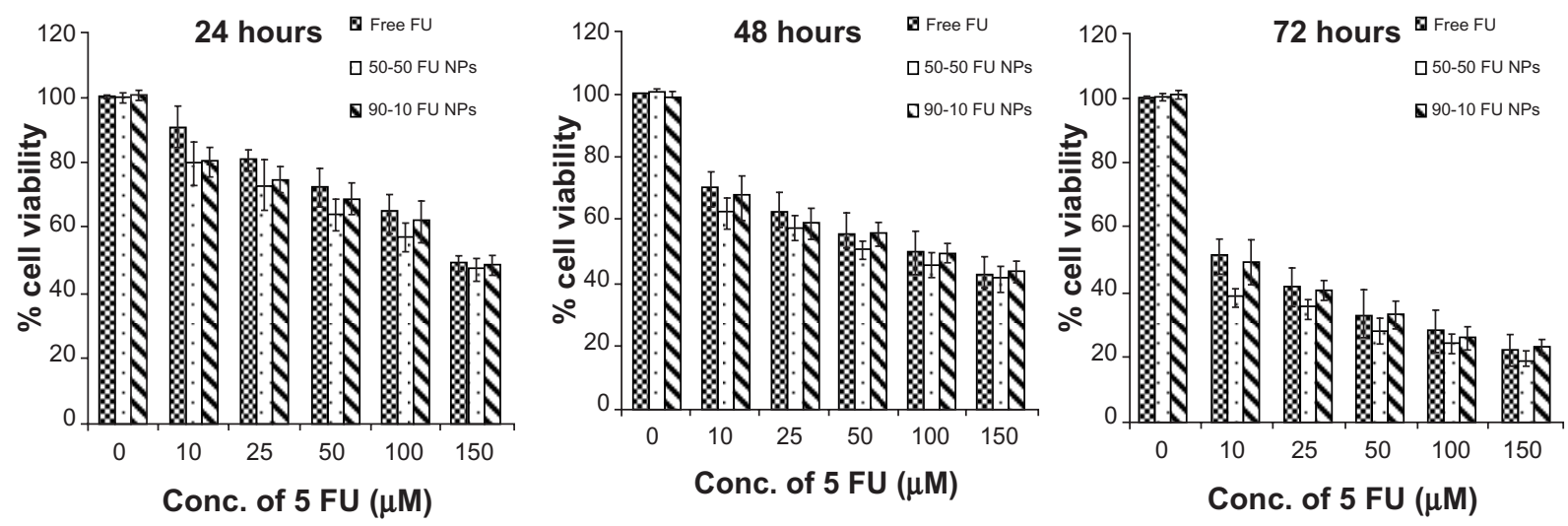

Figure 9 Cell viability of MCF7 cells treated with 5-FU-entrapped PLGA 50-50 and 90-10 NPs compared with free 5-FU (mean \pm standard deviation; $\mathrm{n}=6$ ). Abbreviations: Conc, concentration; FU, 5-fluorouracil; NP, nanoparticle; PLGA, poly (D, L-lactic-co-glycolic acid). 

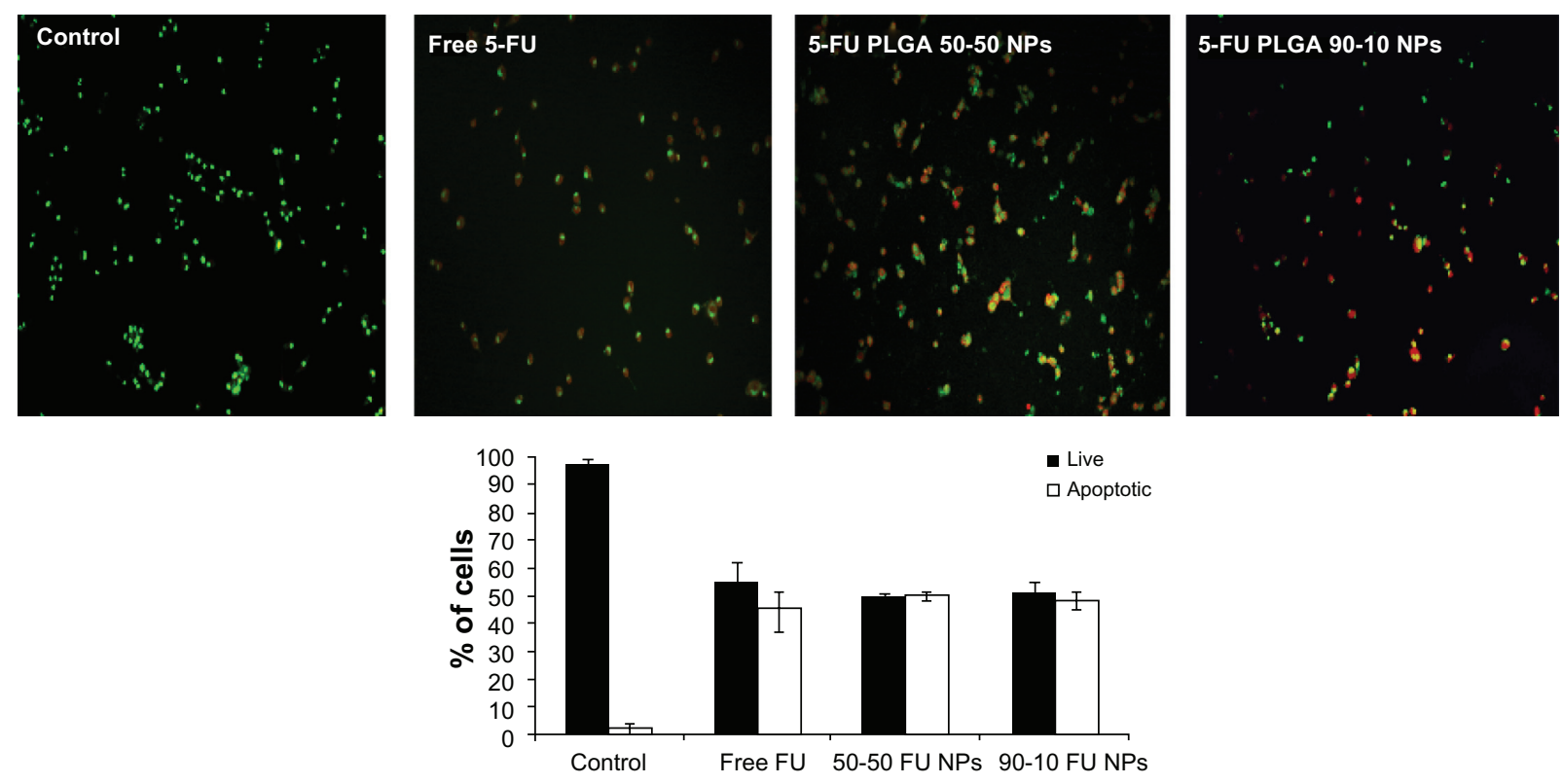

Figure 10 Fluorescence images of U87MG cells stained with acridine orange/ethidium bromide followed by quantification of apoptosis based on morphology changes. Abbreviations: FU, 5-fluorouracil; NP, nanoparticle; PLGA, poly (D, L-lactic-co-glycolic acid).

In the present work, 5-FU PLGA nanoparticles were prepared using a modified solvent evaporation method, ${ }^{34}$ and a comparative study was done using two different lactide/ glycolide combinations, 50-50 and 90-10. The nanoparticles were successfully prepared with considerably good encapsulation efficiency ${ }^{25}$ and high yield. From the TEM images (Figure 1) and size distribution graph (Figure 2), it was shown that particles with spherical size and uniform size distribution were obtained. Compared with blank PLGA nanoparticles, entrapment of 5-FU caused a slight increase in the size and zeta potential, which might be due to the presence of free drug on the particle surface. It was observed that variation in the lactide to glycolide ratio of the nanoparticles did not show any significant variation in the drug encapsulation, size, yield, and zeta potential, both combinations showing almost similar parameters (Table 1). Absence of drug peak in the DSC results (Figure 3 ) suggested the presence of 5-FU in molecular dispersion form inside the polymer matrix. ${ }^{35}$
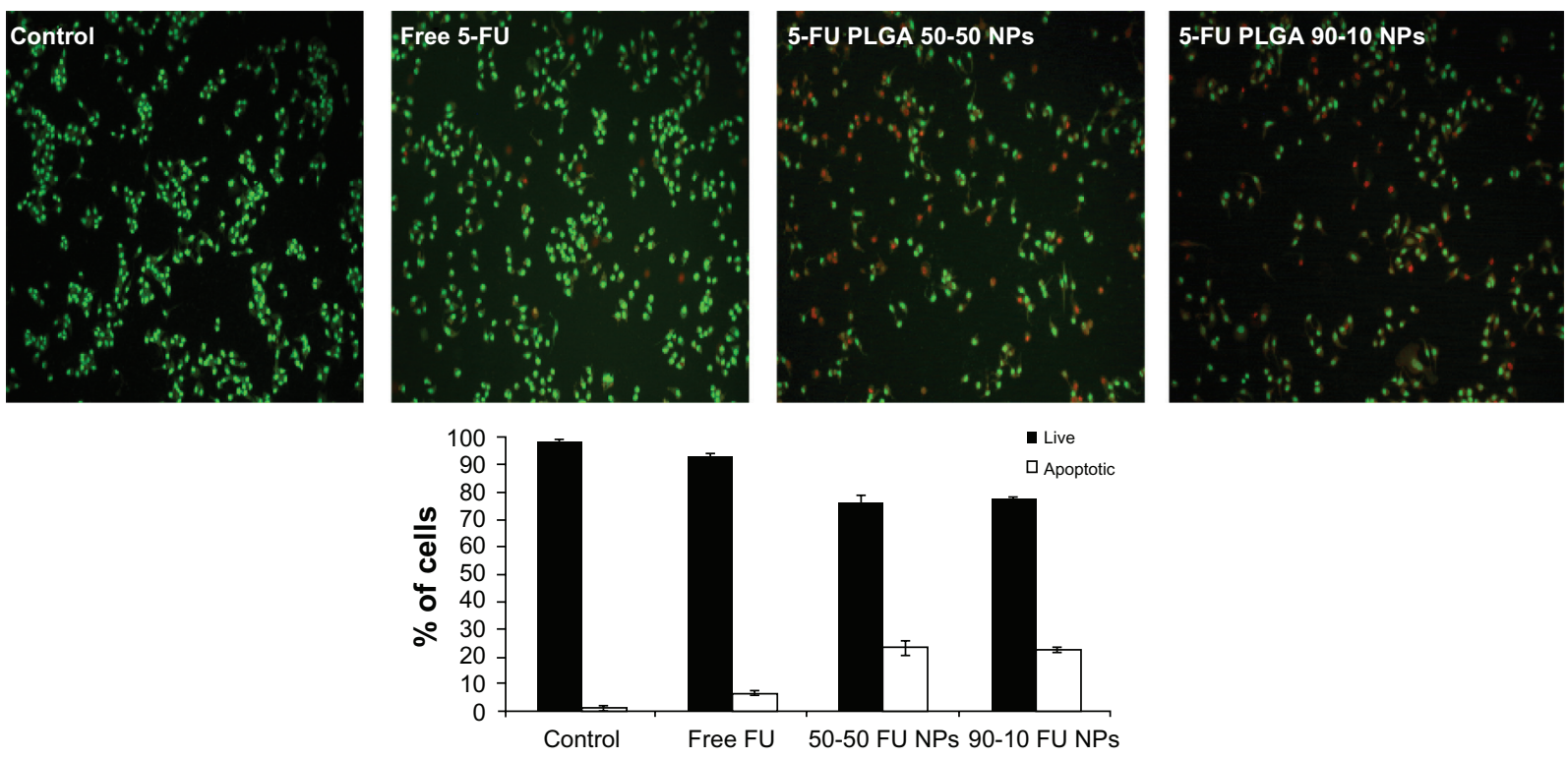

Figure II Fluorescence images of MCF7 cells stained with acridine orange/ethidium bromide followed by quantification of apoptosis based on morphology changes. Abbreviations: FU, 5-fluorouracil; NP, nanoparticle; PLGA, poly (D, L-lactic-co-glycolic acid). 
U87MG

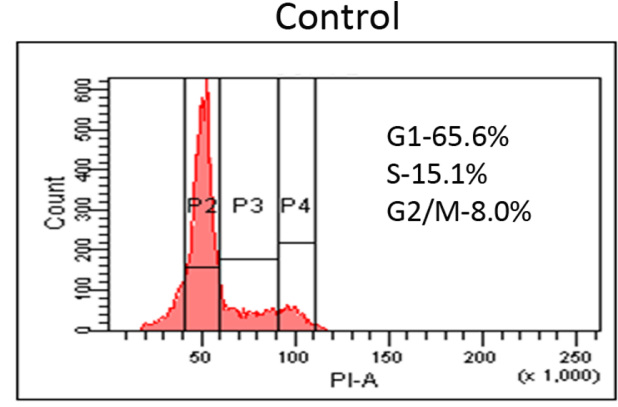

5-FU PLGA 50-50 NPs

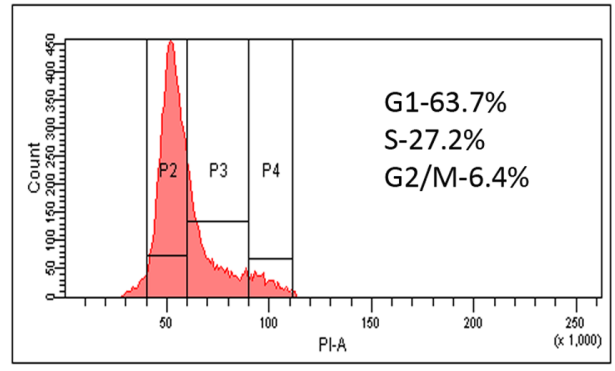

MCF7

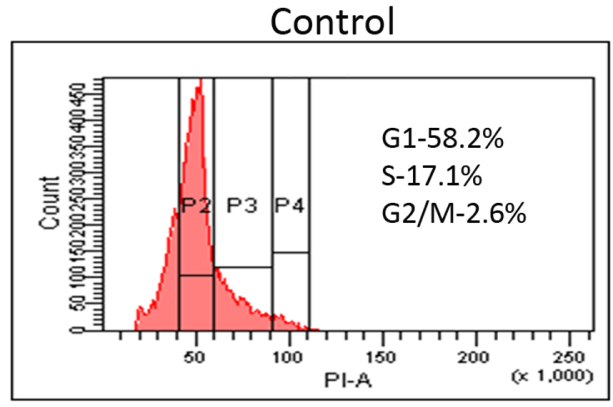

5-FU PLGA 50-50 NPs

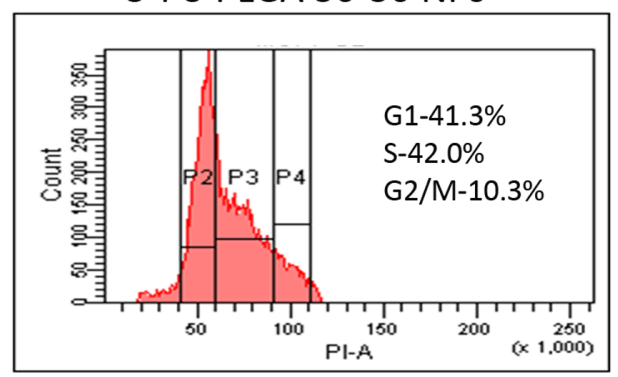

Free 5-FU

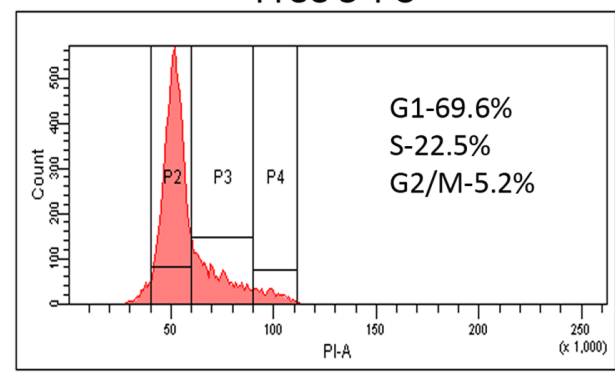

5-FU PLGA 90-10 NPs

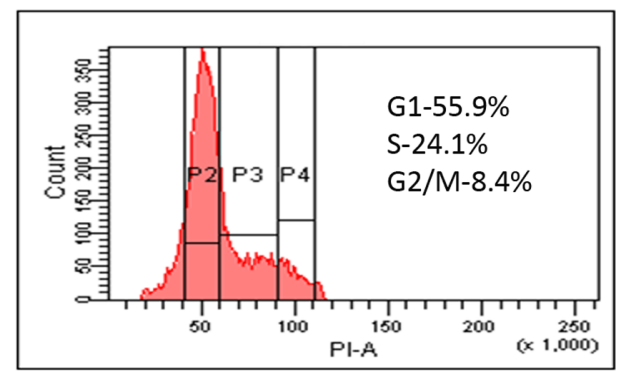

Free 5-FU

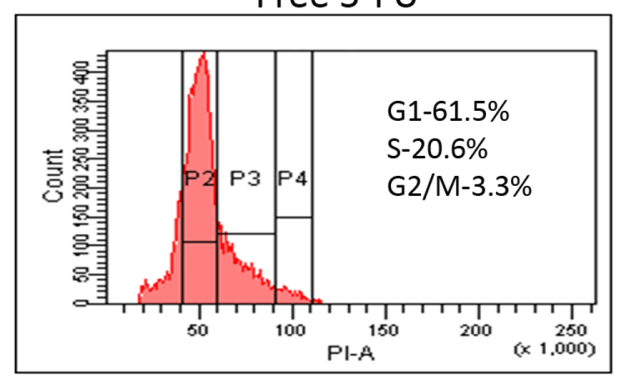

5-FU PLGA 90-10 NPs

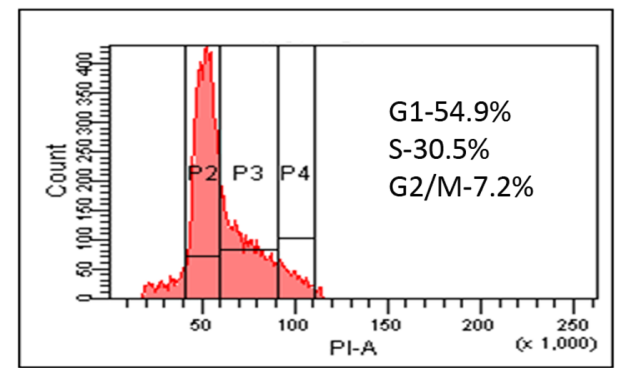

Figure 12 Cell-cycle analysis of U87MG (A) and MCF7 (B) cells on treatment with different 5-FU formulations.

Abbreviations: FU, 5-fluorouracil; NP, nanoparticle; PLGA, poly (D, L-lactic-co-glycolic acid).

The thermograms demonstrated that there is no interaction between the drug and the polymer, 5-FU, maintaining its crystalline nature. This data is important because the presence of drug in molecular dispersion form helps in its sustained release. ${ }^{36}$ This was further confirmed by the absence of a 5-FU peak in the X-ray diffractograms of the nanoparticle formulation (Figure 4). To analyze the dependence of PLGA combination on drug release, in vitro release studies were conducted. In agreement with previous reports, ${ }^{18,37}$ PLGA 50-50 nanoparticles showed faster in vitro release of 5-FU compared with PLGA 90-10 (Figure 5), which might be due to the presence of higher glycolide content in the 50-50 combination that accounts for its faster degradability.

Since 5-FU is reported to be effective in the treatment of brain cancers ${ }^{32,38}$ and breast cancer, ${ }^{39,40}$ glioblastoma (U87MG) and breast adenocarcinoma (MCF7) cell lines were 
selected for the biological evaluation of these nanoparticles. Since 5-FU is a nonfluorescent drug, the intracellular uptake of nanoparticles was shown by encapsulating rhodamine dye in PLGA nanoparticles using both the combinations. For contrast to the red color of rhodamine, nuclei were stained with DAPI which stains blue. Incubation of the cells with $10 \mu \mathrm{mol} / \mathrm{L}$ of nanoparticles for just 2 hours showed considerable red intracellular fluorescence in both the cell lines (Figures 6 and 7). Also, both the PLGA combinations showed efficient uptake, indicating the independence of cellular uptake from lactide/glycolide ratio of PLGA. Cell viability studies conducted for three different time durations showed that nanoparticles induced a clear dose as well as time-dependent growth inhibition in both the cell lines (Figures 8 and 9), with PLGA 50-50 nanoparticles showing the highest cytotoxicity. Among various methods used to detect apoptosis, chromatin condensation and nuclear fragmentation remain the hallmarks of apoptotic cells, since it allows distinguishing viable, early or late apoptotic and necrotic cells. In $\mathrm{AO} / \mathrm{EB}$ double staining, $\mathrm{AO}$ permeates all cells and makes the nuclei appear green, whereas EB stains the nucleus red only when cytoplasmic membrane integrity is lost. Thus, live cells show a normal green nucleus; early apoptotic cells a bright green nucleus with condensed or fragmented chromatin; late apoptotic cells show condensed and fragmented orange chromatin; and cells that have died from direct necrosis show a structurally normal orange nucleus. ${ }^{27,28}$ Our results of AO/ EB staining also exhibited a higher number of apoptotic cells on treatment with PLGA 50-50 nanoformulation (Figures 10 and 11) compared with free 5-FU and PLGA 90-10 nanoparticles. Since 5-FU interferes with DNA synthesis, ${ }^{41}$ the alterations in cell cycle progression on treatment with 5-FU formulations were studied using fluorescence-activated cell sorting (FACS) analysis. In the case of the U87MG cell line, it was seen that the ratio of cells arrested in the S phase was higher on nanoparticle treatment $(27.2 \%$ and $24.1 \%)$ compared with the arrest caused by the same concentration of free drug $(22.5 \%)$. Similarly, MCF7 cells showed a significant S phase arrest on treatment with nanoparticles ( $42 \%$ and $30.5 \%)$, which was considerably higher than the arrest caused by free 5 -FU (20.6\%) (Figure 12). This explains the better efficiency of 5-FU entrapped PLGA nanoparticles compared with free 5-FU. Here also, in agreement with our previous results, PLGA 50-50 nanoparticles induced the highest cell arrest. Since blank PLGA nanoparticles are nontoxic, their data for $\mathrm{AO} / \mathrm{EB}$ staining and FACS is not shown. Analysis of the results of cytotoxicity studies followed by AO/EB assay and FACS depict that PLGA 50-50 nanoparticles showed better potency than 90-10 nanoparticles in both the cell lines, indicating the variation in cytotoxicity with the lactide/glycolide combination of PLGA used. Although the potential of 5-FU-loaded PLGA microspheres has already been reported, ${ }^{38,42-44}$ limitations associated with their size restrict their efficacy in cancer therapy. Since data from the literature show that continuous infusion of low-doses is an excellent regimen for inducing cell death more effectively than a single high-dose exposure ${ }^{45}$ it supports the idea that nanoparticle-based sustained-release formulations could be very promising in improving the efficacy of therapeutic agent. Also, we report for the first time the dependence of lactide/glycolide ratio on the anticancer activity of drugentrapped PLGA nanoparticles. Since leaky vasculature and poor lymphatic drainage present in most tumors ${ }^{46}$ facilitates the entry of nanosized particles, ${ }^{47}$ our results support the rationale behind using 5-FU nanoformulations in medical cancer therapeutics.

\section{Conclusion}

5-FU-loaded PLGA nanoparticles were prepared to overcome the side effects associated with overdosing and sizeassociated limitations of microspheres in chemotherapy. In a novel study, the dependence of monomeric ratio of the carrier PLGA on potency was evaluated by preparing 5-FU nanoparticles with two different monomeric ratios of PLGA, 50-50 and 90-10. Particles with the two ratios mainly differed in their drug release kinetics, with PLGA 50-50 showing faster release. A cytotoxicity study followed by $\mathrm{AO} / \mathrm{EB}$ assay and FACS analysis clearly demonstrated the superior efficiency of these nanoparticles to induce apoptosis in glioma (U87MG) and breast cancer (MCF7) cells compared with free drug. Notably, variation in the lactide/ glycolide combination of PLGA varied the extent of drug release, which altered the ability of nanoparticles to induce cell death. This resulted in higher efficacy of PLGA 50-50 nanoparticles to cause apoptosis compared with 90-10. Thus, our results clearly demonstrate that 5-FU-entrapped PLGA nanoparticles can open new frontiers for clinical therapeutics in cancer chemotherapy.

\section{Acknowledgments}

The authors are thankful to the National Institute of Interdisciplinary Sciences and Technology, Kerala, for DSC and XRD studies and CSIR, New Delhi, for providing a Senior Research Fellowship to Lekha Nair K. 


\section{Disclosure}

The authors report no conflicts of interest in this work.

\section{References}

1. Ozols RF, Herbst RS, Colson YL, et al. Clinical cancer advances 2006: major research advances in cancer treatment, prevention, and screening - a report from the American Society of Clinical Oncology. J Clin Oncol. 2007;25:146-162.

2. Hubbell JA. Materials science: enhancing drug function. Science. 2003;300:595-596.

3. Cai C, Zhou K, Wu Y, Wu L. Enhanced liver targeting of 5-fluorouracil using galactosylated human serum albumin as a carrier molecule. J Drug Target. 2006;14:55-61.

4. Cao S, Rustum YM. Synergistic antitumor activity of irinotecan in combination with 5-fluorouracil in rats bearing advanced colorectal cancer: role of drug sequence and dose. Cancer Res. 2000;60: 3717-3721.

5. Kubota T. Recent progress in combination therapy of low-dose CDDP/5-FU in Japan. Theoretical basis for low-dose CDDP/5-FU therapy. Jpn J Cancer Chemother. 1999;26:1536-1541.

6. Shapiro WR, Green SB, Burger PC, et al. A randomized comparison of intra-arterial versus intravenous with or without intravenous 5-fluorouracil, for newly diagnosed patients with malignant glioma. J Neurosurg. 1992;76:772-781.

7. Hutchins LF, Green SJ, Ravdin PM, et al. Randomized, controlled trial of cyclophosphamide, methotrexate, and fluorouracil versus cyclophosphamide, doxorubicin, and fluorouracil with and without tamoxifen for high-risk, node-negative breast cancer: treatment results of Intergroup Protocol INT-0102. J Clin Oncol. 2005;23:8313-8321.

8. Longley DB, Harkin DP, Johnston PG. 5-fluorouracil: mechanisms of action and clinical strategies. Nat Rev Cancer. 2003;3:330-338.

9. Parker WB, Cheng YC. Metabolism and mechanism of action of 5-fluorouracil. Pharmacol Ther. 1990;48:381-395.

10. Fata F, Ron IG, Kemeny N, O’Reilly E, Klimstra D, Kelsen DP. 5-fluorouracil-induced small bowel toxicity in patients with colorectal carcinoma. Cancer. 2000;86:1129-1134.

11. Paolo AD, Danesi R, Falcone A, et al. Relationship between 5-fluorouracil disposition, toxicity and dihydropyrimidine dehydrogenase activity in cancer patients. Ann Oncol. 2001;12:1301-1306.

12. van Kuilenburg ABP, Haasjes J, Richel DJ, et al. Clinical implications of dihydropyrimidine dehydrogenase (DPD) deficiency in patients with severe 5-fluorouracil-associated toxicity: identification of new mutations in the DPD gene. Clin Cancer Res. 2000;6:4705-4712.

13. Boisdron-Celle M, Menei PH, Benoit JP. Preparation and characterization of 5-fluorouracil-loaded microparticles as biodegradable anticancer drug carriers. J Pharm Pharmacol. 1995;47:108.

14. Cho SH, Lee HB. Preparation of 5-fluorouracil-loaded poly (L-lactide-co-glycolide) wafer and evaluation of in vitro release behavior. Macromolecular Res. 2003;11:183-188.

15. Wang G, Tucker IG, Roberts MS, Hirst LW. In vitro and in vivo evaluation in rabbits of a controlled release 5-fluorouracil subconjunctival implant based on poly (D, L-lactide-co-glycolide). Pharm Res. 1996;13:1059-1064.

16. Lee JS, Chae GS, Kimb MS, Cho SH, Lee HB, Khang G. Degradation behaviour in vitro for poly (D, L-lactide-co-glycolide) as drug carrier. Biomed Mater Eng. 2004;14:185-192.

17. Makino K, Nakajima T, Shikamura M, et al. Efficient intracellular delivery of rifampicin to alveolar macrophages using rifampicin-loaded PLGA microspheres: effects of molecular weight and composition of PLGA on release of rifampicin. Colloids Surf B Biointerfaces. 2004;36:35-42.

18. Yoo JY, Kim JM, Khang G, et al. Effect of lactide/glycolide monomers on release behaviors of gentamicin sulfate-loaded PLGA discs. Int J Pharm. 2004;276:1-9.
19. Lemaire L, Roullin VG, Franconi F, et al. Therapeutic efficacy of 5-fluorouracil-loaded microspheres on rat glioma: a magnetic resonance imaging study. NMR Biomed. 2001;14:360-366.

20. Menei P, Boisdron-Celle M, Croué A, Guy G, Benoit JP. Effect of stereotactic implantation of biodegradable 5-fluorouracil-loaded microspheres in healthy and C6 glioma-bearing rats. Neurosurgery. 1996;39:117-123.

21. Menei P, Venier MC, Gamelin E, et al. Local and sustained delivery of 5 fluorouracil from biodegradable microspheres for the radiosensitization of glioblastoma. Cancer. 1999;86:325-330.

22. Kim JH, Kim YS, Park K, et al. Antitumor efficacy of cisplatin-loaded glycol chitosan nanoparticles in tumor-bearing mice. J Control Release. 2008; 127:41-49.

23. Upadhyay KK, Bhatt AN, Mishra AK, et al. The intracellular drug delivery and anti tumor activity of doxorubicin loaded poly ([gamma]benzyl 1-glutamate)-b-hyaluronan polymersomes. Biomaterials. 2010;31:2882-2892.

24. Zhu Z, Li Y, Li X, et al. Paclitaxel-loaded poly (N-vinylpyrrolidone)-bpoly ([epsilon]-caprolactone) nanoparticles: preparation and antitumor activity in vivo. J Control Release. 2010;142:438-446.

25. Li S, Wang A, Jiang W, Guan Z. Pharmacokinetic characteristics and anticancer effects of 5-fluorouracil loaded nanoparticles. BMC Cancer. 2008;8:103-111.

26. Selvaraj V, Alagar M. Analytical detection and biological assay of antileukemic drug 5-fluorouracil using gold nanoparticles as probe. Int J Pharm. 2007;337:275-281.

27. Baskic D, Popovic S, Ristic P, Arsenijevic NN. Analysis of cycloheximide-induced apoptosis in human leukocytes: fluorescence microscopy using annexin $\mathrm{V} /$ propidium iodide versus acridin orange/ethidium bromide. Cell Biol Int. 2006;30:924-932.

28. Ribble D, Goldstein NB, Norris DA, Shellman YG. A simple technique for quantifying apoptosis in 96-well plates. BMC Biotechnol. 2005;5:12.

29. Kuropkat C, Griem K, Clark J, Rodriguez ER, Hutchinson J, Taylor SGT. Severe cardiotoxicity during 5-fluorouracil chemotherapy: a case and literature report. Am J Clin Oncol. 1999;22:466-470.

30. De Angelis PM, Svendsrud DH, Kravik KL, Stokke T. Cellular response to 5-fluorouracil(5-FU) in 5-FU-resistant colon cancer cell lines during treatment and recovery. Mol Cancer. 2006;5:20-45.

31. He YC, Chen JW, Cao J, Pan DY, Qiao JG. Toxicities and therapeutic effect of 5-fluorouracil controlled release implant on tumor-bearing rats. World J Gastroenterol. 2003;9:1795-1798.

32. Fournier E, Passirani C, Colin N, Breton P, Sagodira S, Benoit JP. Development of novel 5-FU-loaded poly (methylidene malonate 2.1. 2)-based microspheres for the treatment of brain cancers. Eur J Pharm Biopharm. 2004;57:189-197.

33. Fournier E, Passirani C, Montero Menei C, et al. Therapeutic effectiveness of novel 5 fluorouracil loaded poly (methylidene malonate 2.1. 2) based microspheres on F98 glioma bearing rats. Cancer. 2003;97:2822-2829.

34. Desgouilles S, Vauthier C, Bazile D, et al. The design of nanoparticles obtained by solvent evaporation: a comprehensive study. Langmuir. 2003;19:9504-9510.

35. Jain A, Jain SK. In vitro and cell uptake studies for targeting of ligand anchored nanoparticles for colon tumors. Eur J Pharm Sci. 2008;35:404-416.

36. Panyam J, Williams D, Dash A, Leslie-Pelecky D, Labhasetwar V. Solid-state solubility influences encapsulation and release of hydrophobic drugs from PLGA/PLA nanoparticles. J Pharm Sci. 2004;93: 1804-1814.

37. Duvvuri S, Gaurav Janoria K, Mitra AK. Effect of polymer blending on the release of ganciclovir from PLGA microspheres. Pharm Res. 2006;23:215-223.

38. Roullin VG, Deverre JR, Lemaire L, et al. Anti-cancer drug diffusion within living rat brain tissue: an experimental study using [3H](6)-5-fluorouracil-loaded PLGA microspheres. Eur J Pharm Biopharm. 2002;53:293-299. 
39. Marchal JA, Boulaiz H, Suárez I, et al. Growth inhibition, G 1-arrest, and apoptosis in MCF-7 human breast cancer cells by novel highly lipophilic 5-fluorouracil derivatives. Invest New Drugs. 2004;22:379-389.

40. Okamoto S, Sakai M, Uchida J, Saito H. 5-Florouracil induces apoptotic cell death with G2 phase arrest in human breast cancer grafted in nude mice. Anticancer Res. 1996;16:2699-2704.

41. Yoshikawa R, Kusunoki M, Yanagi H, et al. Dual antitumor effects of 5-fluorouracil on the cell cycle in colorectal carcinoma cells: a novel target mechanism concept for pharmacokinetic modulating chemotherapy. Cancer Res. 2001;61:1029-1037.

42. Roullin VG, Lemaire L, Venier-Julienne MC, Faisant N, Franconi F, Benoit JP. Release kinetics of 5-fluorouracil-loaded microspheres on an experimental rat glioma. Anticancer Res. 2003;23:21-25.

43. Roullin VG, Mege M, Lemaire L, et al. Influence of 5-fluorouracil-loaded microsphere formulation on efficient rat glioma radiosensitization. Pharm Res. 2004;21:1558-1563.
44. Sastre RL, Olmo R, Teijón C, Muñíz E, Teijón JM, Blanco MD. 5-Fluorouracil plasma levels and biodegradation of subcutaneously injected drug-loaded microspheres prepared by spray-drying poly (D, L-lactide) and poly (D, L-lactide-co-glycolide) polymers. Int J Pharm. 2007;338:180-190.

45. Kishimoto S, Kawazoe Y, Ikeno M, Fukushima S, Takeuchi Y. Continuous exposure to low-dose cisplatin and apoptosis. Biological Pharm Bull. 2005;28:1954-1957.

46. Maeda H, Wu J, Sawa T, Matsumura Y, Hori K. Tumor vascular permeability and the EPR effect in macromolecular therapeutics: a review. J Control Release. 2000;65:271-284.

47. Fukumura D, Jain RK. Tumor microvasculature and microenvironment: targets for anti-angiogenesis and normalization. Microvasc Res. 2007;74:72-84.
International Journal of Nanomedicine

\section{Publish your work in this journal}

The International Journal of Nanomedicine is an international, peerreviewed journal focusing on the application of nanotechnology in diagnostics, therapeutics, and drug delivery systems throughout the biomedical field. This journal is indexed on PubMed Central,

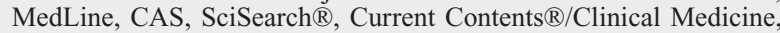

\section{Dovepress}

Journal Citation Reports/Science Edition, EMBase, Scopus and the Elsevier Bibliographic databases. The manuscript management system is completely online and includes a very quick and fair peer-review system, which is all easy to use. Visit http://www.dovepress.com/ testimonials.php to read real quotes from published authors.

Submit your manuscript here: http://www.dovepress.com/international-journal-of-nanomedicine-journal 